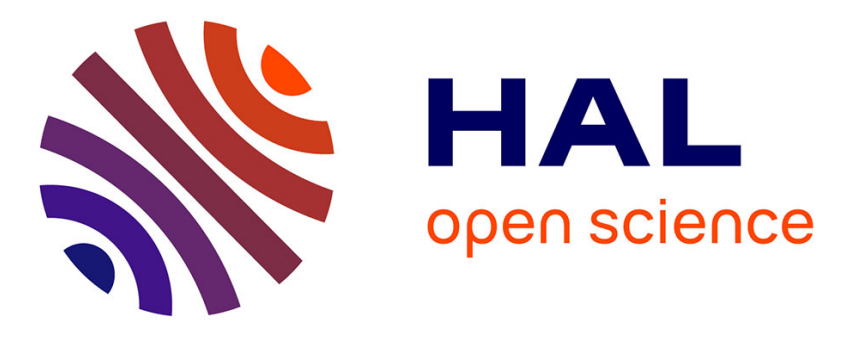

\title{
Third-order nonlinearity in Ge-Sb-Se glasses at mid-infrared wavelengths
}

Liyan Chen, Feifei Chen, Shixun Dai, Guangming Tao, Lihe Yan, Xiang Shen, Hongli Ma, Xianghua Zhang, Yinsheng Xu

\section{- To cite this version:}

Liyan Chen, Feifei Chen, Shixun Dai, Guangming Tao, Lihe Yan, et al.. Third-order nonlinearity in Ge-Sb-Se glasses at mid-infrared wavelengths. Materials Research Bulletin, 2015, 70, pp.204-208. 10.1016/j.materresbull.2015.04.048 . hal-01231154

HAL Id: hal-01231154 https://hal-univ-rennes1.archives-ouvertes.fr/hal-01231154

Submitted on 28 Jan 2016

HAL is a multi-disciplinary open access archive for the deposit and dissemination of scientific research documents, whether they are published or not. The documents may come from teaching and research institutions in France or abroad, or from public or private research centers.
L'archive ouverte pluridisciplinaire HAL, est destinée au dépôt et à la diffusion de documents scientifiques de niveau recherche, publiés ou non, émanant des établissements d'enseignement et de recherche français ou étrangers, des laboratoires publics ou privés. 


\section{Third-order nonlinearity in Ge-Sb-Se glasses at}

\section{mid-infrared wavelengths}

Liyan Chen ${ }^{\mathrm{a}}$, Feifei Chen ${ }^{\mathrm{a}}$, Shixun Dai ${ }^{\mathrm{a}}$, Guangming Tao ${ }^{\mathrm{b}}$, Lihe Yan ${ }^{\mathrm{c}}$, Xiang Shen ${ }^{\mathrm{a}}$, Hongli Ma ${ }^{\mathrm{d}}$, Xianghua Zhang ${ }^{\mathrm{d}}$, and Yinsheng $\mathrm{Xu}^{\mathrm{a}}$ * xuyinsheng@nbu.edu.cn

${ }^{a}$ Laboratory of Infrared Materials and Devices, The Research Institute of Advanced Technologies, Ningbo University, Ningbo 315211, China

${ }^{b}$ CREOL, The College of Optics \& Photonics, University of Central Florida, Orlando, Florida 32816, United States

${ }^{c}$ School of Electronics \& Information Engineering, Xi'an Jiaotong University, No. 28, Xianning West Road, Xi'an, 710049, China

${ }^{d}$ Laboratory of Glass and Ceramics, UMR CNRS 6226, University of Rennes I, 35042 Rennes Cedex, France

*Corresponding Author. Tel.: +86 57487609870.

Graphical abstract

The nonlinearity of Ge-Sb-Se glasses at mid-infrared wavelengths are researched by Z-Scan technique and the large FOM $(>10)$ of $\mathrm{Ge}_{20} \mathrm{Sb}_{10} \mathrm{Se}_{70}$ glass shows the greatest potential for mid-IR all optical switching devices. 


\section{Highlights}

- The nonlinearity properties of Ge-Sb-Se glasses at mid-IR were explored.

- The third order nonlinearity increased with the refractive index at $1550 \mathrm{~nm}$.

- The highest $\mathrm{n}_{2}$ is found at $2000 \mathrm{~nm}$.

- FOM of $\mathrm{Ge}_{20} \mathrm{Sb}_{10} \mathrm{Se}_{70}$ glass is larger than 10 at mid-IR wavelengths.

Abstract: The optical properties of Ge-Sb-Se glasses have been extensively studied at telecom wavelengths in recent years. However, the understanding of nonlinearity in Ge-Sb-Se glasses at mid-infrared wavelengths still remains limited. In this work, a series of $\mathrm{Ge}_{20} \mathrm{Sb}_{\mathrm{x}} \mathrm{Se}_{80-\mathrm{x}}(\mathrm{x}=0,5,10)$ glasses were prepared by conventional melt-quenching method. The absorption spectra and the refractive index of glasses were recorded. The third order nonlinearity, $n_{2}$, and nonlinear absorption coefficient were measured for $\mathrm{Ge}-\mathrm{Sb}$-Se glass samples at the wavelengths of 1550,2000 and $2500 \mathrm{~nm}$ by Z-scan technique, respectively. With the increasing of $\mathrm{Sb}$ contents, the linear refractive index of glass increased. Among the three operating wavelengths, all the three glass samples have a highest $n_{2}$ at $2000 \mathrm{~nm}$. By using the figure of merit (FOM) to evaluate the studied three glasses, the $\mathrm{Ge}_{20} \mathrm{Sb}_{10} \mathrm{Se}_{70}$ glass shows the greatest potential for mid-IR all optical switching devices.

Keywords: chalcogenide; glass; nonlinear optics; optical materials; 


\section{Introduction}

All-optical signal processing is seen as critical for future telecommunication networks to address the growing demand for network flexibility, low cost, energy consumption, etc. [1] To realize all-optical switching (AOS), materials with large Kerr nonlinearity, ultrafast response time, as well as low linear, and nonlinear losses are required. Typically, transparent glasses with large nonlinearity are excellent candidates for $\operatorname{AOS}[2,3]$. As well known, the presence of atoms with large polarizability (e.g. Sb atom) in the glass composition increases the nonlinear refractive index of the material. Gómez et al. have investigated five wavelengths between 1400-1600 $\mathrm{nm}$ and reported the $n_{2}$ of $\mathrm{Sb}_{2} \mathrm{O}_{3}-\mathrm{SbPO}_{4}$ glass operating in the range $1.6-4.1 \times 10^{-15} \mathrm{~cm}^{2} / \mathrm{W}$ [4]. Compared with oxide glass, chalcogenide glasses possess some superior optical properties, such as high linear refractive index $(2.0-3.0$ at $1.55 \mu \mathrm{m})$, wide IR transmission window (from visible to $10-20 \mu \mathrm{m}$ ), large nonlinear refractive index $(\times 100-\times 1000$ of silica $)$ and ultrafast optical response $(\sim 100$ fs), which make them excellent candidates for the third-order nonlinear optical materials [5-9]. In the past few years, near-IR and short-wave IR nonlinear optical properties of chalcogenide glasses, namely, the nonlinear refraction index $\left(n_{2}\right)$, have been extensively studied. Wang et al. have reported that $n_{2}$ of $\mathrm{As}_{2} \mathrm{~S}_{3}$ at $1.25 \mu \mathrm{m}$ and $1.55 \mu \mathrm{m}$ is $3.0 \times 10^{-17} \mathrm{~m}^{2} / \mathrm{W}$ and $2.3 \times 10^{-17} \mathrm{~m}^{2} / \mathrm{W}$, respectively [10]. However, the characterization of the nonlinear (NL) optical 
absorption and NL refraction of chalcogenide glass has been limited to the wavelengths of visible or near-IR less than $1686 \mathrm{~nm}$ [11].

The multi-photon absorption (MPA) places a basic limitation on the efficiency of any high nonlinear refraction index $\left(n_{2}\right)$ materials in AOS schemes based on an intensity dependent refractive index, especially the strong two-photon absorption (TPA) in chalcogenide glasses. At telecom wavelengths, relatively high peak intensity is usually demanded to initiate the third order Kerr nonlinearity, simultaneously lead to a strong TPA. As a result, the high Kerr nonlinearity and relatively weaker MPA beyond the TPA region come to a combination, which makes chalcogenide glasses highly promising for nonlinear applications at mid-IR wavelengths $[10,12]$. The enormous research on the supercontinuum generation from near-IR to mid-IR also demands the nonlinear properties of chalcogenide glasses at mid-IR wavelengths.

Nonlinear refraction (NLR) and TPA coefficient can be measured by Zscan technique [13], in which a sample is scanned near the focal region of a focused laser beam. With the sample is moved along the propagation direction of the laser beam (Z-axis), it consequently experiences a phase and intensity modulation, which can be observed in its transmittance measured as a function of the sample position (z). If all the transmitted light is measured, only TPA affects the Z-scan. In this case, it refers to as open-aperture Z-scan. If part of 
the transmitted light is detected due to the presence of an aperture in front of the detector, both NLR and TPA indicate themselves on a so-called closedaperture Z-scan. For the sake of getting the NLR index, the TPA value that is obtained from an open-aperture Z-scan must be taken into account in the closed aperture Z-scan modeling [14, 15].

This paper reports on the measurements of the third-order nonlinearity of a compositional series of Ge-Sb-Se chalcogenide glasses using the Z-scan technique at the wavelengths of $1550 \mathrm{~nm}, 2000 \mathrm{~nm}$ and $2500 \mathrm{~nm}$, respectively. Values of nonlinear refractive index $\left(n_{2}\right)$ and TPA or three-photon absorption coefficient (3PA) at corresponding wavelengths were obtained.

\section{Experiment}

In this experiment, a series of $\mathrm{Ge}_{20} \mathrm{Sb}_{\mathrm{x}} \mathrm{Se}_{80-\mathrm{x}}(\mathrm{x}=0,5,10)$ glasses were prepared by a conventional melt-quenching method in a vacuumed silica ampoule. The high purity raw materials, Ge (99.999\%), Sb (99.999\%), and Se (99.999\%), were carefully weighed, transferred into quartz ampoules and sealed in a vacuum at $2 \times 10^{-3} \mathrm{~Pa}$. The quartz ampoules with the raw materials were heated in rocking furnaces at $950{ }^{\circ} \mathrm{C}$ for $12 \mathrm{~h}$ to ensure homogenization of the mixture. Then the ampoules were quenched in water. In order to reduce stress and improve optical homogeneity, the glasses were annealed at temperature $10{ }^{\circ} \mathrm{C}$ below glass transition temperature $\left(T_{\mathrm{g}}\right)$ for $2 \mathrm{~h}$ and cooled down with a rate of $10{ }^{\circ} \mathrm{C} / \mathrm{h}$ to room temperature. Glass rods were obtained 
from the ampoules and cut into discs of $1 \mathrm{~mm}$ and $0.5 \mathrm{~mm}$. These were then polished for optical studies.

The linear refractive indices from 1.7 to $15 \mu \mathrm{m}$ were measured using Metricon 2010 Prism Coupler with an accuracy of \pm 0.001 , and the nonlinearities were measured with the Z-scan technique. Both of them were measured using the $1 \mathrm{~mm}$ thick samples. In the process of Z-scan experiment, the optical parametric amplifier, which is pumped by an $800 \mathrm{~nm}$ Ti:sapphire laser producing $\approx 150 \mathrm{fs}$ laser pulses at a repetition rate of $1 \mathrm{kHz}$, was tuned to operate at three wavelengths of 1550,2000 , and $2500 \mathrm{~nm}$, and the incident energy of single laser pulse was kept at $128 \pm 10 \mathrm{~nJ}$. The measurements were repeated ten times at different places on the sample surface to minimize experimental error. To realize the technique, the laser beam was focused by a $12 \mathrm{~cm}$ focal distance lens. Besides, the sample which was fixed in a computercontrolled translation stage was to be scanned in the focus region along the beam propagation direction (Z-axis). Negative values of $\mathrm{Z}$ correspond to locations of the sample between the focusing lens and its focal plane. A photo detector with an adjustable aperture in front of the sample was placed in the far-field region. The aperture size with radius $r_{\mathrm{a}}$ is related to the linear aperture transmittance by

$$
S=\left[1-\exp \left(-2 r_{a}^{2} / w_{a}^{2}\right)\right]
$$


with $w_{\mathrm{a}}$ denoting the beam radius at the aperture for very low incident power. A closed-aperture Z-scan experiment corresponds to $S<1$, which is employed for $n_{2}$ measurements, while $S=1$ is used for the determination of $\alpha_{2}[16,17]$.

The MPA coefficient and nonlinear refractive index $n_{2}$ are obtained by analyzing open- and closed-aperture measurements, respectively [18-20]. In the case of open-aperture detection, the detected signal shows a valley-only trace, which indicates the existence of nonlinear MPA, depending on the wavelengths. By contrast, when the detection is carried out with the presence of aperture, the detected signal has a peak-valley trace, depending on the strength of nonlinear refraction at the focal point. The normalized transmittance can be obtained by integrating the intensity $I$. The total timeintegrated transmission for the open aperture is theoretically fitted with equations (2) and (3) obtained from the derivations for MPA coefficients by Sutherland et al [12].

$$
T_{\text {open }}(z)=-\frac{1}{2 \sqrt{2}} \frac{\beta I_{0} L_{\text {eff }}}{1+\left(z / z_{0}\right)^{2}}
$$

where $\mathrm{z}$ is the longitudinal scan distance from the focal point of a Gaussian beam with an on-axis peak intensity of $I_{0}$ and $\mathrm{z}_{0}$ is the confocal beam parameter; $L_{e f f}=\alpha^{-1}\left(1-e^{-\alpha L}\right)$ is the effective optical length, where $\alpha$ is the linear absorption coefficient for the samples and $L$ is the sample thickness. For closed aperture z-scan a circular aperture with $S<1$ is placed behind the 
sample, and the transmission is recorded as a function of $\mathrm{z}$ position. For small absorptive and refractive changes the transmissivity is given by,

$$
\mathrm{T}_{\text {closed }}(\mathrm{z})=1-\frac{8 \pi}{\sqrt{2} \lambda} \frac{z / z_{o}(1-S)^{0.25} L_{e f f} n_{2} I_{0}}{\left[1+\left(z / z_{0}\right)^{2}\right]\left[9+\left(z / z_{0}\right)^{2}\right]}-\frac{1}{2 \sqrt{2}} \frac{L_{e f f} \beta I_{0}\left[3-\left(z / z_{0}\right)^{2}\right]}{\left[1+\left(z / z_{0}\right)^{2}\right]\left[9+\left(z / z_{0}\right)^{2}\right]}
$$

\section{Results and discussion}

As can be seen in Fig. 1, optical absorption spectra of $\mathrm{Ge}-\mathrm{Sb}$-Se glass samples $(0.5 \mathrm{~mm})$ were recorded from $500 \mathrm{~nm}$ to $2500 \mathrm{~nm}$. We can find that the absorption edge $\lambda_{\text {vis }}$, defined as the absorption coefficient at $10 \mathrm{~cm}^{-1}$, are $803,811,914 \mathrm{~nm}$, respectively. With the glass content of Sb increasing from 0 to $10 \mathrm{~mol} . \%$, it moves to the longer wavelengths.

In the absorption spectrum of the glass, optical absorption in the ultraviolet region is decided by the intrinsic absorption of matrix inside, photon energy which is corresponded to the absorption edge is defined as the optical band gap $[21,22]$. In recent years, optical band gap $\left(E_{\mathrm{g}}\right)$ of glasses has been considered having a great correlation with third-order nonlinear properties [23-25]. Related research results suggested that glasses with a narrower optical band gap usually have higher third-order nonlinear properties. Chen et al. have reported that in the glass network of $\mathrm{Bi}_{2} \mathrm{O}_{3}-\mathrm{B}_{2} \mathrm{O}_{3}-\mathrm{BaO}$, weakening the $\mathrm{B}-\mathrm{O}$ bands result in lowering optical band gap and enhancing third-order nonlinearity [26]. In addition, $\mathrm{Xu}$ et al. have studied third-order optical nonlinear characterizations of $\mathrm{Bi}_{2} \mathrm{O}_{3}-\mathrm{B}_{2} \mathrm{O}_{3}-\mathrm{TiO}_{2}$ ternary glasses, and came to a 
conclusion that $n_{2}$ decreases with the increasing of $E_{\mathrm{g}}$ in $\mathrm{BBT}_{x}(x=1,2,3)$ glasses [27]. Here, $E_{\mathrm{g}}$ was obtained from ultraviolet absorption edge related to electron transition between conduction band and valence band with Tauc equation. To measure the optical band gap $E_{\mathrm{g}}$, it is necessary to use relatively thin glass samples of $0.5 \mathrm{~mm}$. According to the classical Tauc equation, $E_{\mathrm{g}}$ can be calculated through the absorption spectrum of the glass. Its expression is as follows,

$$
\alpha \mathrm{h} v=\mathrm{B}\left(\mathrm{h} v-\mathrm{E}_{g}\right)^{m}
$$

where $\alpha$ is the linear absorption coefficient, $h v$ is the incident photon energy, $\mathrm{B}$ is the electronic transition constant, exponent $m$ is a parameter related to electron transition species caused by optical absorption. $\mathrm{m}=0.5$ represents a direct allowed optical transitions $\left(E_{\mathrm{dg}}\right)$, while $\mathrm{m}=2$ represents indirect allowed optical transitions $\left(E_{\mathrm{ig}}\right)[26,28]$. Figs. $2 \mathrm{a}$ and $2 \mathrm{~b}$ describe $E_{\text {ig }}$ and $E_{\mathrm{dg}}$ of the Ge-Sb-Se glass samples, respectively. Some information can be acquired directly from the experimental curves: with the $\mathrm{Sb}$ content increases from $0 \%$ to $10 \%$, the value of $E_{\text {ig }}$ decreases from $1.71 \mathrm{eV}$ to $1.66 \mathrm{eV}$, and the value of $E_{\mathrm{dg}}$ decreases from $1.62 \mathrm{eV}$ to $1.57 \mathrm{eV}$. According to the above conclusion, this behavior indicates that the $\mathrm{Ge}_{20} \mathrm{Sb}_{10} \mathrm{Se}_{70}$ glass have the highest $n_{2}$ among these Ge-Sb-Se glass samples. The material parameters for the $\mathrm{Ge}-\mathrm{Sb}$-Se glass samples are summarized in Table I. 
According to Miller's rule and Ref [11], the nonlinearity of one material can be estimated from the refractive index $n_{0}$ by following equation,

$$
n_{2}=\wedge \rho 7 \times 1 n^{-16} \frac{\left(n_{0}^{2}-1\right)^{4}}{n_{0}^{2}} \mathrm{~mm}^{2} / \mathrm{\Lambda}
$$

According to equation (5), the nonlinearity at different wavelengths can be estimated. Fig. 3 shows the dependence of refractive index $n_{0}$ and the nonlinear refractive index $n_{2}$ on the wavelength, respectively. Clearly, both of them decreased with increasing wavelength. However, the estimated tendency of the $n_{2}$ does not agree with the following results obtained by Z-scan technique.

When conducting the Z-scan experiment, the corresponding closed-aperture and open-aperture were executed at $1550 \mathrm{~nm}, 2000 \mathrm{~nm}$, and $2500 \mathrm{~nm}$, respectively. Typical closed-aperture $(S=0.05)$ and open-aperture $(S=1) Z$ scan curves of the $\mathrm{Ge}_{20} \mathrm{Sb}_{5} \mathrm{Se}_{75}$ are shown in Fig. 4, respectively. Due to very weak signal, the open-aperture Z-scan curve of $\mathrm{Ge}_{20} \mathrm{Sb}_{5} \mathrm{Se}_{75}$ at $2500 \mathrm{~nm}$ cannot be obtained and is not shown here. As can be seen in Figs. 4a-c, the peak with a valley configuration manifests the self-defocusing behavior of the sample, namely, the positive value of nonlinear refraction. Meanwhile, the observed transmittance changes between the pre-focal $(\mathrm{Z}<0)$ minimum and the post-focal $(\mathrm{Z}>0)$ maximum in the closed $\mathrm{Z}$-scan are due to the positive nonlinear indices of refraction of the samples $[29,30]$. Further, it is evident that the $\mathrm{Ge}_{20} \mathrm{Sb}_{5} \mathrm{Se}_{75}$ glass sample shows larger $n_{2}$ in terms of its larger 
distance between peak and valley [14]. The gap between the normalized transmittance valley and the peak is largest in the curve of $2000 \mathrm{~nm}$ wavelength. The evident asymmetry between valley and peak in closedaperture curve informed the presence of nonlinear absorption of the chalcogenide glasses, which was confirmed by the downward tendency of optical transmittance in the open-aperture Z-scans. The same behaviors were also observed in other samples.

The open-aperture Z-scan shown in Figs. 4d-e illustrates the intensitydependent transmission of the $\mathrm{Ge}_{20} \mathrm{Sb}_{5} \mathrm{Se}_{75}$. It can be seen that the optical transmission of the $\mathrm{Ge}_{20} \mathrm{Sb}_{5} \mathrm{Se}_{75}$ shows a decreasing tendency as it approached the laser focus $(z=0)$, namely nonlinear absorption occurred as the laser density increased. At the MIR wavelengths of 2000 and $2500 \mathrm{~nm}$, the most important experimental result found in open-aperture Z-scans is the presence of three-photon absorption (3PA) [31].

By fitting the curves with a classic procedure [18-20], the nonlinear refractive index, $n_{2}$, and the TPA (or 3PA) coefficient, $\alpha_{2}$ (or $\alpha_{3}$ ), of the three samples at 1550, 2000 and $2500 \mathrm{~nm}$ are calculated and listed in Table II, respectively. To ensure the accuracy of the measurements, the nonlinearity propertied of $\mathrm{As}_{2} \mathrm{Se}_{3}$ glass at $1550 \mathrm{~nm}$ was referred. We can find that with the increase of operating wavelength, the values of $n_{2}$ increase first and then decrease. The largest value of $n_{2}$ is found at $2000 \mathrm{~nm}$ for all the three samples. 
From Table 1, the bandgap of the three glasses ranges from 1.71 to $1.66 \mathrm{eV}$ for $E_{\mathrm{ig}}$ (or 1.62 to $1.57 \mathrm{eV}$ for $E_{\mathrm{dg}}$ ). For the present chalcogenides, the large 3PA at $2000 \mathrm{~nm}$ can be attributed to electron band-to-band transition type since $1 / 3 E_{\mathrm{g}}$ of the studied chalcogenide glasses is comparable to the $h v$ at 2000 $\mathrm{nm}(h v=0.62 \mathrm{eV})$ and smaller than it, thus $n_{2}$ behaviors of the chalcogenide glasses at $2000 \mathrm{~nm}$ is increased significantly when approaching to the 3PA resonance and the $n_{2}$ values are higher than those obtained from $1550 \mathrm{~nm}$. As the wavelength goes to $2500 \mathrm{~nm}$, as a result of the small photon energy $(h v=$ $0.496 \mathrm{eV}$ ) that is below $1 / 3 E_{\mathrm{g}}$ of the three samples, therefore, origination of the 3PA at $2500 \mathrm{~nm}$ is defect absorption tail below the band gap, namely from Urbach absorption region. The weak Urbach type 3PA resulted in lower nonlinear refraction by the KK relations [18]; and consequently the smallest $n_{2}$ value among the three testing wavelengths.

Usually, figure of merit (FOM) is used to evaluate the performance of the nonlinear optical material. Since the main limitation of the chalcogenide glasses to be applied in AOS at mid-IR wavelengths is the TPA and 3PA, FOM can be expressed by $n_{2} /\left(\alpha_{2} \lambda\right)$ and $n_{2} /\left(\alpha_{3} \lambda I_{0}\right)\left(I_{0}\right.$ is the laser intensity at focus) for TPA and 3PA dominant materials, respectively. Normally, FOM $>1$ can be designed to the AOS devices while the FOM $>10$ is ideal for efficient all-optical devices [32]. As presented in Table II, the FOMs at $2000 \mathrm{~nm}$ for $\mathrm{Ge}_{20} \mathrm{Sb}_{10} \mathrm{Se}_{70}$ glass and at $2500 \mathrm{~nm}$ for $\mathrm{Ge}_{20} \mathrm{Sb}_{5} \mathrm{Se}_{75}$ and $\mathrm{Ge}_{20} \mathrm{Sb}_{10} \mathrm{Se}_{70}$ glasses 
satisfy the criterion for all-optical devices (FOM $>10$ ). Hence, the $\mathrm{Ge}_{20} \mathrm{Sb}_{10} \mathrm{Se}_{70}$ can be selected for the mid-IR AOS devices.

\section{Conclusions}

In summary, we prepared a series of $\mathrm{Ge}-\mathrm{Sb}$-Se glass samples and investigated the TPA and third order nonlinearity at mid-IR wavelengths of 1550, 2000 and $2500 \mathrm{~nm}$ using Z-scan experiments with femtosecond laser pulses, respectively. With the increasing $\mathrm{Sb}$ contents, the linear refractive index increased. Among the three operating wavelengths, all the three glass samples have a highest $n_{2}$ at $2000 \mathrm{~nm}$. By using the figure of merit (FOM) to evaluate the studied three glasses, the $\mathrm{Ge}_{20} \mathrm{Sb}_{10} \mathrm{Se}_{70}$ glass shows the greatest potential for mid-IR all optical switching devices.

\section{Acknowledgments}

The Project Sponsored by the National Natural Science Foundation of China (Nos. 61205181, 61308094, 61377061), the State Key Program of National Natural Science of China (No. 61435009), Scientific Research Foundation for the Returned Overseas Chinese Scholars, State Education Ministry, and K. C. Wong Magna Fund in Ningbo University.

\section{References}

[1] M.D. Pelusi, F. Luan, E. Magi, M.R. Lamont, D.J. Moss, B.J. Eggleton, J.S. Sanghera, L.B. Shaw, I.D. Aggarwal, Opt. Express, 16 (2008) 1150611512. 
[2] K.B. Manjunatha, R. Dileep, G. Umesh, M.N. Satyanarayan, B. Ramachandra Bhat, Opt. Mater., 36 (2014) 1054-1059.

[3] A. Ajami, M.S. Rafique, N. Pucher, S. Bashir, W. Husinsky, R. Liska, R. Inführ, H. Lichtenegger, J. Stampfl, S. Lüftenegger, Proc. SPIE 7027, 15th International School on Quantum Electronics: Laser Physics and Applications, 70271H (December 19, 2008);

[4] L.A. Gómez, C.B. de Araújo, D. Messias, L. Misoguti, S. Zilio, M. Nalin, Y. Messaddeq, J. App. Phys., 100 (2006) 116105.

[5] R.W. Boyd, Academic Press, New York, 2008.

[6] A.A. Wilhelm, C. Boussard-Plédel, Q. Coulombier, J. Lucas, B. Bureau, P. Lucas, Adv. Mater., 19 (2007) 3796-3800.

[7] L. Calvez, H. Ma, J. Lucas, X. Zhang, Adv. Mater., 19 (2007) 129-132.

[8] Y.-S. Xu, J.-W. Cheng, J.-N. Qi, S.-S. Lu, K.-L. Lu, J.-W. Xu, Q.-F. Shao, S.-X. Dai, J. Inorg. Mater., 29 (2014) 735-740.

[9] W. Wei, R. Wang, X. Shen, L. Fang, L.D. Barry, J. Phys. Chem. C, 117 (2013) 16571-16576.

[10] T. Wang, V. Nalla, G. Jacek, Y. Cui, G. Qian, W. Ji, D.T. Tan, Opt. Express, 21 (2013) 32192-32198.

[11] T. Wang, X. Gai, W. Wei, R. Wang, Z. Yang, X. Shen, S. Madden, B. Luther-Davies, Opt. Mater. Express, 4 (2014) 1011-1022.

[12] A.D. Bristow, N. Rotenberg, H.M. Van Driel, Appl. Phys. Lett., 90 (2007) 191104-191104-191103. 
[13] W.C. Hurlbut, Y.S. Lee, K.L. Vodopyanov, P.S. Kuo, M.M. Fejer, Opt. Lett., 32 (2007) 668-670.

[14] M. Yin, H. Li, S. Tang, W. Ji, Appl. Phys. B, 70 (2000) 587-591.

[15] S.V. Rao, N.K.M.N. Srinivas, D.N. Rao, L. Giribabu, B.G. Maiya, R. Philip, G.R. Kumar, Opt. Commun., 182 (2000) 255-264.

[16] S. Pramodini, Y.N. Sudhakar, M. Selvakumar, P. Poornesh, Laser Phys., $24(2014) 045408$.

[17] S. Pramodini, P. Poornesh, Opt. Laser Technol., 63 (2014) 114-119.

[18] M. Sheik-Bahae, A.A. Said, T.-H. Wei, D.J. Hagan, E.W.V. Stryland, IEEE J. Quantum Electron., 26 (1990) 760-769.

[19] M. Yin, H.P. Li, S.H. Tang, W. Ji, Appl. Phys. B, 70 (2000) 587-591 .

[20] T. Wang, N. Venkatram, J. Gosciniak, Y. Cui, G. Qian, W. Ji, D.T.H. Tan, Opt. Express, 21 (2013) 32192-32198.

[21] E.S. Sazali, M.R. Sahar, S.K. Ghoshal, R. Arifin, M.S. Rohani, A. Awang, J. Alloys Compd., 607 (2014) 85-90.

[22] V. Ivanova, Y. Trifonova, P. Petkov, T. Petkova, Optoelectron. Adv. Mat., 8 (2014) 42-44.

[23] H. Ahn, M.T. Lee, Y.M. Chang, Appl. Phys. Lett., 104 (2014).

[24] I. Fuks-Janczarek, R. Miedzinski, M.G. Brik, A. Majchrowski, L.R. Jaroszewicz, I.V. Kityk, Solid State Sci., 27 (2014) 30-35.

[25] R. Bala, A. Agarwal, S. Sanghi, N. Singh, Opt. Mater., 36 (2013) 352356. 
[26] F. Chen, S. Dai, Q. Nie, T. Xu, X. Shen, X. Wang, Journal Wuhan University of Technology, Mater. Sci. Ed., 24 (2009) 716-720.

[27] T. Xu, F. Chen, S. Dai, N. Qiuhua, X. Shen, W. Xunsi, Physica B, 404 (2009) 2012-2015.

[28] F. Chen, B. Song, C. Lin, S. Dai, J. Cheng, J. Heo, Mater. Chem. Phys., 135 (2012) 73-79.

[29] F. Chen, T. Xu, S.X. Dai, Q. Nie, X. Shen, X. Wang, B. Song, J. NonCryst. Solids, 356 (2010) 2786-2789.

[30] X. Zheng, M. Feng, Z. Li, Y. Song, H. Zhan, J. Mater. Chem. C, 2 (2014) $4121-4125$.

[31] B. Gu, J. Wang, J. Chen, Y.-X. Fan, J. Ding, H.-T. Wang, Opt. Express, 13 (2005) 9230-9234.

[32] A. Zakery, S.R. Elliott, Optical nonlinearities in chalcogenide glasses and their applications, Springer, 2007. 


\section{Figure captions}

Fig. 1. Absorption spectra of Ge-Sb-Se glass samples.

Fig. 2. Indirect allowed optical band gap (a) and direct allowed optical band gap (b) of the Ge-Sb-Se glass samples, respectively.

Fig. 3. The dependence of refractive index $n_{0}$ (a) and the nonlinear refractive index $n_{2}(\mathrm{~b})$ on the wavelength, respectively.

Fig. 4. Closed-aperture Z-scan curves (a-c) of $\mathrm{Ge}_{20} \mathrm{Sb}_{5} \mathrm{Se}_{75}$ at 1550, 2000, and $2500 \mathrm{~nm}$, respectively. Open-aperture Z-scan curves (d-e) of $\mathrm{Ge}_{20} \mathrm{Sb}_{5} \mathrm{Se}_{75}$ at 1550 and $2000 \mathrm{~nm}$, respectively. 
Table I. Material parameters for the Ge-Sb-Se glass samples.

\begin{tabular}{cccccc}
\hline Samples & $E_{\mathrm{ig}} / \mathrm{eV}$ & $E_{\mathrm{dg}} / \mathrm{eV}$ & $\lambda_{\text {vis }} / \mathrm{nm}$ & $T_{\mathrm{g}} /{ }^{\circ} \mathrm{C}$ & Density $/ \mathrm{g} . \mathrm{cm}^{-3}$ \\
\hline $\mathrm{Ge}_{20} \mathrm{Se}_{80}$ & 1.71 & 1.62 & 803 & 163.7 & 4.47 \\
$\mathrm{Ge}_{20} \mathrm{Sb}_{5} \mathrm{Se}_{75}$ & 1.68 & 1.59 & 811 & 188.0 & 4.51 \\
$\mathrm{Ge}_{20} \mathrm{Sb}_{10} \mathrm{Se}_{70}$ & 1.66 & 1.57 & 914 & 216.5 & 4.63 \\
\hline
\end{tabular}

Table II. $n_{2}, \alpha_{2}$ and $\alpha_{3}$ of the Ge-Sb-Se glass samples at 1550, 2000 and $2500 \mathrm{~nm}$,

respectively.

\begin{tabular}{|c|c|c|c|c|c|c|c|c|c|c|}
\hline \multirow[b]{2}{*}{ Samples } & \multicolumn{3}{|c|}{$1500 \mathrm{~nm}$} & \multicolumn{3}{|c|}{$2000 \mathrm{~nm}$} & \multicolumn{4}{|c|}{$2500 \mathrm{~nm}$} \\
\hline & $\begin{array}{c}n_{2} \\
/ 10^{-18} \mathrm{~m}^{2} \cdot \mathrm{W}^{-1}\end{array}$ & $\begin{array}{c}\alpha_{2} \\
/ 10^{-13} \mathrm{~m} \cdot \mathrm{W}^{-1}\end{array}$ & FOM & $\begin{array}{c}n_{2} \\
/ 10^{-18} \mathrm{~m}^{2} \cdot \mathrm{W}^{-1}\end{array}$ & $\begin{array}{c}\alpha_{3} \\
/ 10^{-27} \mathrm{~m}^{3} \cdot \mathrm{W}^{-}\end{array}$ & & $110^{-18} \begin{array}{r}n \\
\mathrm{~m}\end{array}$ & $\begin{array}{l}n_{2} \\
\mathrm{~m}^{2} \cdot \mathrm{W}^{-1} /\end{array}$ & $0^{-27} \stackrel{\alpha_{3}}{\mathrm{~m}^{3} \cdot \mathrm{W}^{-}}$ & -2 FOM \\
\hline $\mathrm{Ge}_{20} \mathrm{Se}_{80}$ & 3.72 & 6.01 & 4 & 17.45 & 26.91 & 4 & & .68 & 4.34 & 3.1 \\
\hline $\mathrm{Ge}_{20} \mathrm{Sb}_{5} \mathrm{Se}_{75}$ & 4.29 & 3.14 & 8.8 & 16.56 & 31.82 & 3.3 & & .78 & $<0.5$ & $>10$ \\
\hline $\mathrm{Ge}_{20} \mathrm{Sb}_{10} \mathrm{Se}_{70}$ & 6.22 & 4.78 & 8.4 & 16.72 & 8.83 & 11.8 & & .97 & $<0.5$ & $>10$ \\
\hline $\mathrm{As}_{2} \mathrm{Se}_{3}$ & 10 & 16 & 4 & 25 & 49 & 4.1 & & 4.4 & 29.7 & 0.7 \\
\hline
\end{tabular}

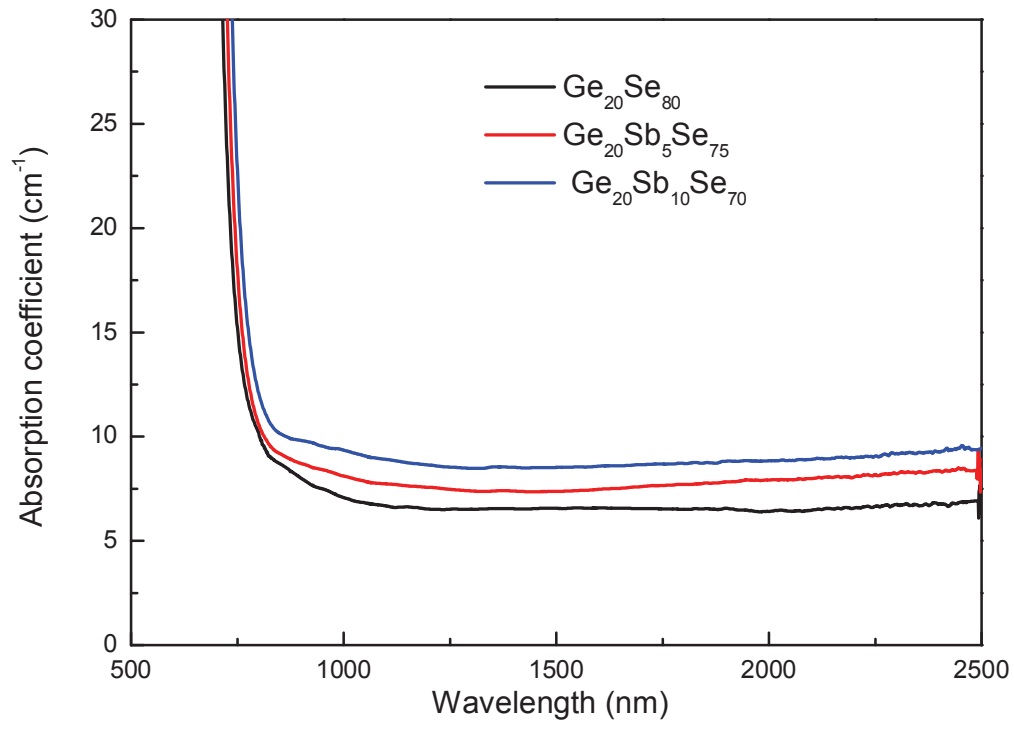

Fig. 1 

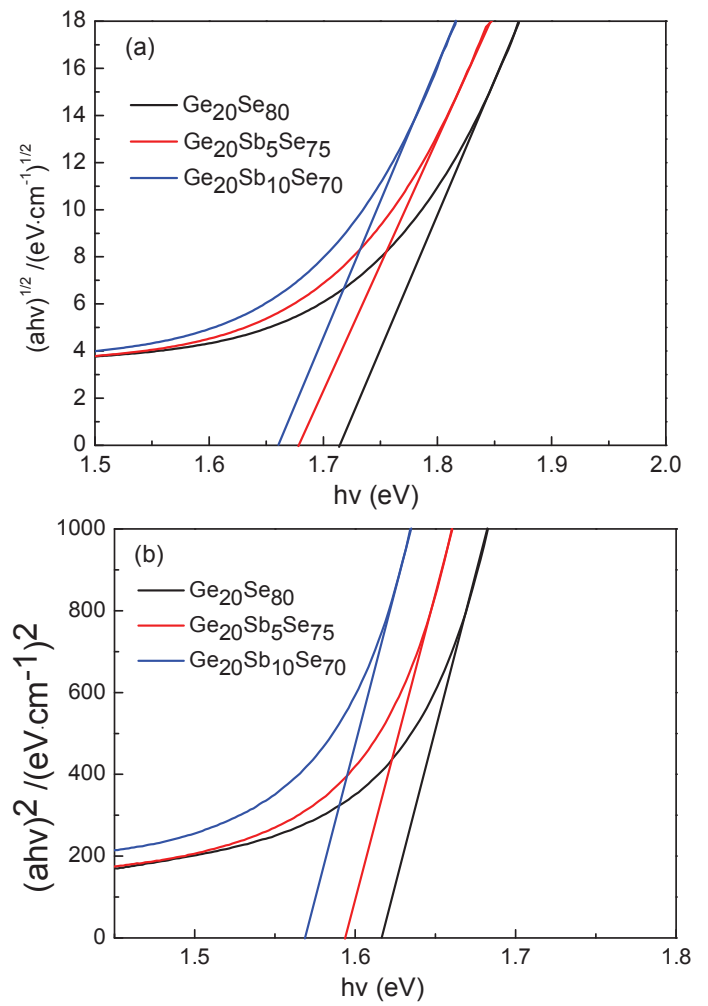

Fig. 2 

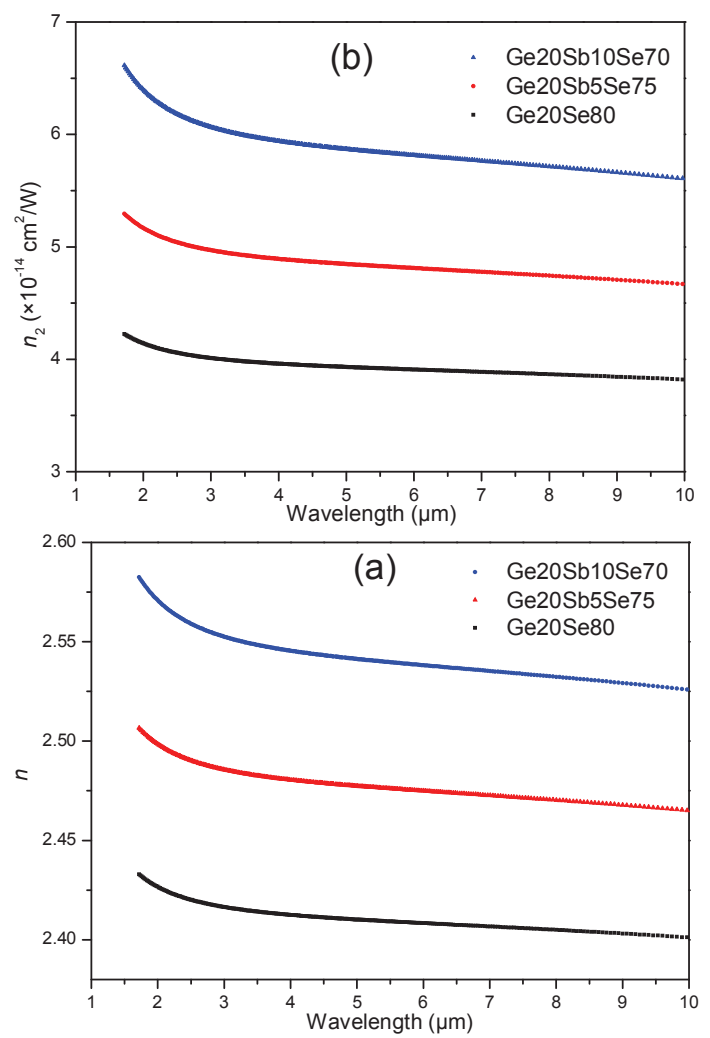

Fig. 3 

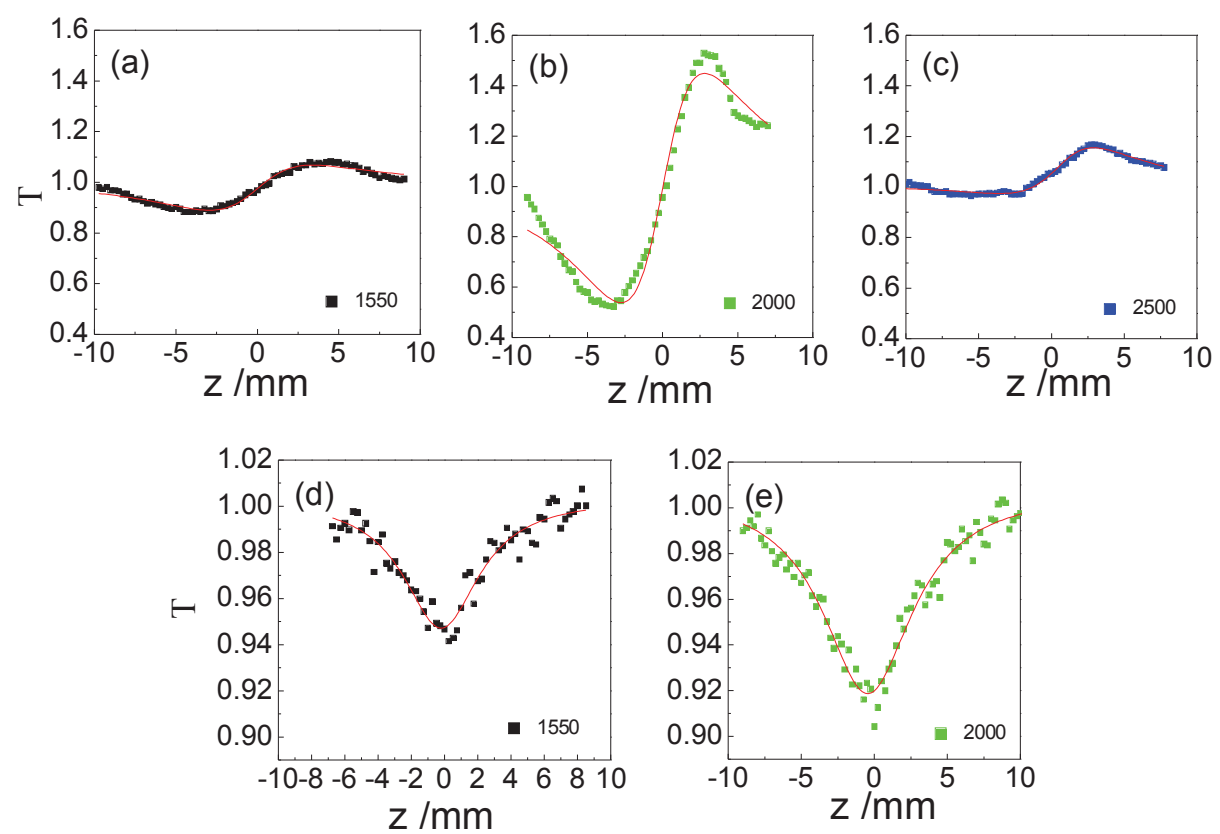

Fig. 4 